\title{
Geography Micro-lecture Situation Investigation and Teaching Strategy Optimization
}

\author{
Zhanhong Liu \\ School of Resources and Environment \\ University of Jinan \\ Jinan, China \\ stu_liuzh@126.com
}

\author{
Fang Dong \\ School of Resources and Environment \\ University of Jinan \\ Jinan, China \\ stu_fangd@ujn.edu.cn
}

\begin{abstract}
Micro-lecture is an emergent teaching method, with the features of problems gathered, outstanding topics, small but forceful, interesting, and interacting, meeting the study characteristics and demands of students. This paper summarizes the teaching processes and strategies of existing Micro-lectures, analyzes the geography Micro-lecture teaching situation and problems on the basis of investigation for current situation. By combining with the features of geography subject, it proposes advice for optimizing geography Micro-lecture teaching strategies in the aspects of teaching time, topics and interesting. It is expected that the application of geography Micro-lecture could greatly improve the learning efficiency of students, change the existing teaching methods, and increase the interesting of study.
\end{abstract}

Keywords-Micro-lecture; Geography; Teaching Strategy; Optimization

\section{INTRODUCTION}

Micro-lecture (also called "Mini-sized Class") is an emergency teaching method, it means using teaching videos in the class to teach around some difficult points, knowledge points or technical skills, so as to achieve more specific teaching results. The concept of "Micro-lecture" is proposed at the earliest by the teaching designer David Penrose in America San Juan Institute in 2008, who proposes the five steps of Micro-lecture creation. It is early and widely applied in western countries, Japan and Singapore in Asia. Micro-lecture has started late in China, and is still at the initial stage.

The geography subject has abundant knowledge points and a very large and complicated knowledge system, the geography knowledge itself has special and dynamic features, every object of geography study is the result of past and the start of future development, they are the regular objects existing in specific space but can't be independent. This requires students to see problems in the perspective of connection while studying geography, and think problems by taking specific space into consideration. Though the traditional geography teaching class could explain knowledge points in details, but could not let students feel the geographical condition or the space and dynamics of knowledge in the process of study, and realize the mystery and meaning of geography subject. The application of Micro-lecture could cleverly reveal the features of geography subject, for example, the viewpoint switching and dynamic

This paper is derived from teaching and research projects of University of Jinan: JZC12107. At the same time, thanks to the School of Resources and Environment for the support of the micro-course teaching and research program. images of Micro-lecture video could reveal the knowledge points to students in a more comprehensive way. Therefore, the application of Micro-lecture would have big influence on the geography teaching.

\section{CURRENT CONDITION AND FEATURES OF GEOGRAPHY MiCRO-LECTURE TEACHING}

Through interviewing, conducting questionnaires for the geography teachers in junior and senior high schools, as well as the relevant data analysis from China Micro-lecture resource network, obtain the first-hand materials about geography Micro-lecture teaching development condition, where there are 100 pieces of teacher questionnaires, 92 pieces of returned effective questionnaires. The content of questionnaires is about Micro-lecture teaching process, methods and time of making Micro-lecture, reference resources, feasibility assessment of applying Micro-lecture. According to the investigation materials, the features of current condition are summarized as below.

\section{A. Integrity of teaching process}

By collecting and analyzing relevant materials about Micro-lecture, the geography Micro-lecture teaching has the same integrity feature as the traditional teaching class, having the feature of integrity, at present, the teaching of Microlecture designed by most teachers includes selection of teaching content, design of teaching plan, design of after-class practices, reflections on teaching, as well as other teaching links[1].

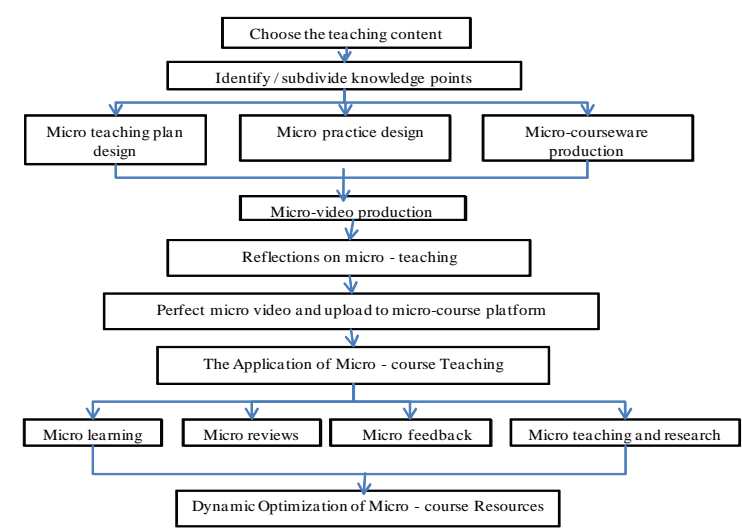

Fig. 1. Micro-lecture subjects distribution diagram 


\section{B. The diversity of Micro-lecture making methods}

Through investigations, it is found that there are several common methods for making Micro-lecture[2]:

- Recorder + blackboard. This method is similar to the teaching method of traditional class, it is the most original Micro-lecture type, and the teaching effects is not satisfactory.

- $\quad$ Recording software + PPT/Flash. This method needs computer, microphone, recording software, Flash or PPT must get ready before recording, it could either presentation + explanation or directly playing, and this method is widely applied.

- Mobile phone + white paper. This method is the simplest Micro-lecture making method, it is applicable to the explanation of subjects like mathematics, physics, and chemistry, but rarely used in geography subject. You can write, draw pictures, make calculation on white paper in the recording process, and reveal the whole ideas in front of students, but this method has high requirements for the pixel and voice quality of mobile phone device.

\section{Richness of Micro-lecture teaching topics}

The regional feature of geography subject and complexity of nature-human elements determines the richness of topics of geography Micro-lectures. It is found that the topics of geography Micro-lecture mainly focus on the teaching of basic knowledge, the important and difficult points in teaching, the content like regional geography location, atmospheric circulation, water circulation, and earth movement could all be expressed through multimedia, properly adding abundant pictures and images, colorful animation and videos with both sounds and images[3].

\section{PROBLEMS EXISTING IN GEOGRAPHY MiCRO-LECTURE TEACHING DEVELOPMENT}

Ever since 2011, our country successively introduces all types of Micro-lecture design contests, Micro-lecture teacher training lectures. However, Micro-lecture is not widely applied in geography teaching, there are still many students who don't have the completely new experience brought by geography Micro-lecture teaching (as shown in Fig.2).

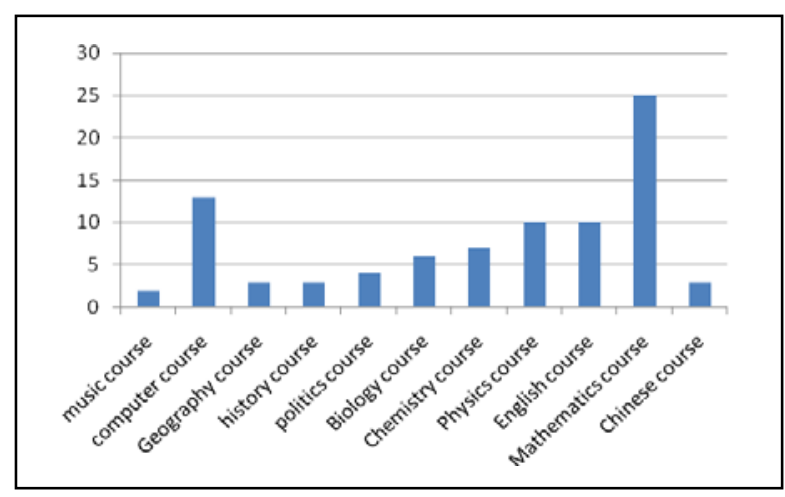

Fig. 2. Micro-lecture subjects distribution diagram
From 289 pieces of returned effective questionnaires aimed at middle school students, we can see only $64.2 \%$ of the students hold approval attitude toward Micro-lecture, thinking Micro-lecture could specialize abstract knowledge, so as to have more intuitive feeling of the knowledge, and study knowledge of different subjects in individualized way.

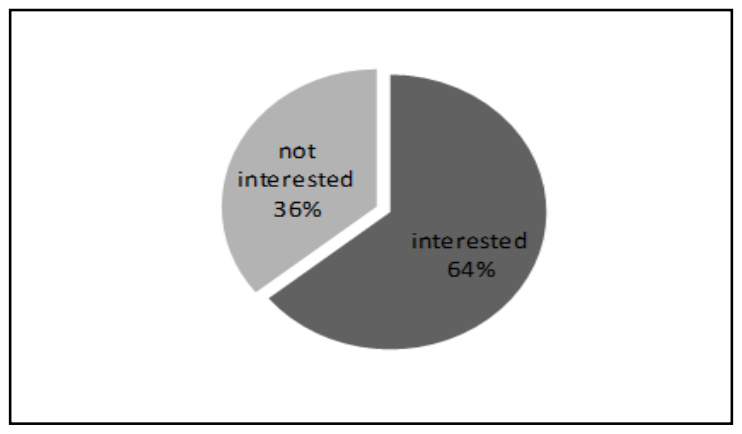

Fig. 3. Diagram of attitudes of middle school students toward Micro-lecture

Why it is difficult to promote geography Micro-lecture and some students do not approve the teaching effect? Through comprehensive investigation and analysis, we summarize the reasons as below.

- In the process from Micro-lecture making to playing, the making of content is very difficult, for example, it is necessary to prepare PPT or flash for recording in advance, and it has very high requirements for teachers and application of multimedia teaching tools. According to the investigation results, when most geography teachers assess their Micro-lectures, they usually mention the problems like "video quality is poor", "non-proficient in video shooting and recording". This is because teachers are not proficient with using the video shooting and recording software, as well as the limitation of software functions, this has become the obstacles for Micro-lecture development.

- In the process of Micro-lecture study, students are the passive recipients, the power of deciding teaching methods is in the hands of teachers, who fail to combine the teaching reflection and students feedback together, and there is less interactions and communications. If students could play the dominant role in the teaching process, choose the method and channel of obtaining knowledge, then the Micro-lecture usage rate would be greatly improved.

- Lack after-class assessment mechanism. Due to the lack of unified and effective Micro-lecture assessment system, the Micro-lectures made by teachers are different in levels, and fail to reflect the geography subject characteristics, but have single form of manifestation, the teaching content is dull and without light points. So the Micro-lecture hasn't played the role it should have -- simplify knowledge, improve the study effects of students, stimulate the study interest of students, even some parents have misunderstanding of this teaching model, and forbid children viewing the Micro-lecture video to reinforce learning after class. 
- Innovative teaching level is low. The supporting resources of Micro-lecture only limit to several types like Micro-lecture teaching plans, exercises, and course-wares, and fail to make effective innovation, lack of effective introduction, concise teaching and proper summary. $89.2 \%$ of the students regard Microlecture as recording and playing of PPT, only $36.2 \%$ of the students could probably use multimedia teaching and other auxiliary tools to provide more lively teaching.

\section{OPTIMIZATION OF GEOGRAPHY MICRO-LECTURE TEACHING} STRATEGY

\section{A. "Micro" is the center of Micro-lecture design}

"Small and forceful" is a big feature of Micro-lecture, one Micro-lecture would teach around one knowledge point. By analyzing the questionnaires results, it is found that students are most concentrated within ten minutes after starting the online course, while most students consider the online courses lasting about forty minutes, and usually close it after opening for several minutes, while the Micro-lecture properly make use of this time period when students are most concentrated, use five to ten minutes to teach the knowledge points, the study efficiency is many times of the ordinary online course and offline courses[4].

\section{B. Pay attention to the topics of geography Micro-lecture}

Topic selection is an important link in Micro-lecture making process, a good topic is extremely easy for teaching and recording, and a poor topic would make the Micro-lecture very dull. One Micro-lecture would teach around one knowledge point; the selection of knowledge point should comply with the purpose of making Micro-lecture: Sharing teaching resources, answer questions of students, inspired teaching. In the meantime, the design of content should be suitable for using multimedia, for example, select the knowledge point of "Reason of Tarim Basin getting dried" to make Micro-lecture, while introducing the geography location and land-sea location of Tarim Basin, use the model of viewpoint switching, switch from the point of Tarim Basin to the Eurasian continent, in this way, its land-sea location is shown clearly. While teaching the moisture is hard to arrive at the basin due to blocking of high mountains, make animation for the moisture, which will become less and less when moving toward the basin, so as to more intuitively reflect the problem of high mountain blocking[5].

\section{The Micro-lecture should be incredibly interesting}

Micro-lecture is different from the traditional class, one reason why its teaching efficiency is higher than the traditional class is the interesting of Micro-lecture, middle school students are easily attracted by animation and videos. Inserting knowledge points into animation or videos could help students naturally master the knowledge points. In the design, and making process of geography Micro-lecture, you can clip the fragments relevant to teaching in columns like Explore and Discover, Approaching Science, Animal World, Come to the Nature broadcast by Central Science and Education Channel, and apply them in the geography Micro-lecture, effectively increase the interesting of Micro-lecture videos and enhance teaching efficiency.

\section{Design of Micro-lecture should combine with geography subject characteristics}

The design of geography Micro-lecture should reflect the spatial, regional, dynamic features of geography subject, rather than simply transfer the knowledge on PPT or blackboard to the video player for playing. Geography subject has not been correctly understood by the society for a long time, but regarded as the one that helps tourism or various strategies; this universal misunderstanding has in-separate relationship with the improper teaching methods and strategies provided by geography teachers in geography teaching. The introduction of geography Micro-lecture could effectively solve this problem. For example, in the physical geography class, the knowledge points as for the formation of water circulation and monsoon could be completely shown to students through viewpoint switching and dynamic images, let students realize the process of geography. The regional geography class could use Micro-lecture to reveal the relationship of nature conditions, economic conditions and social conditions in the region, and let students realize the regional integrity feature of geography subject.

\section{CONCLUSION}

As a teaching innovation, Micro-lecture has got more and more approval and support from the country, schools and the society. Its "micro" feature is the overturn and supplement to traditional teaching, and also an effective way for increasing teaching efficiency.

The geography class in middle school especially needs Micro-lecture teaching model, so as to integrate the abstract concept of mountains and rivers, topography and vegetation, land and sea locations into brief videos, which not only improve the students' efficiency of learning knowledge points, but also deepen and reinforce their mastery degree of knowledge, complying with the subject orientation and features of geography, and helping students make the most effective study within the shortest time.

In the meantime, the geography Micro-lecture teaching also encounter many problems which could not be overlooked -- inaccurate topic selection, less prominent features, single making method which is lack of innovation, however, when there's a problem, there is a solution. By feasibly improve the teaching strategy, teaching methods and making models, make the Micro-lecture more perfect, and further promote Microlecture to the campus, this is the responsibility and mission of every teacher.

\section{REFERENCES}

[1] Eisuke Saito.A conceptual discussion of lesson study from a micropolitical perspective:Implications for teacher development and pupil learning.Teaching and Teacher Education,2013,(2), pp.87-95 
[2] Qin Ranran. The Construction of Evaluation System about Geography Micro-lecture on Middle School. The M.E.Degree, The Central China Normal University, 2016, pp.10-40

[3] Joanne Norcup.Geography education,grey literature and the geographical canon. Journal of Historical Geogarphy, 2015, pp.61-74

[4] Zhou Xianbo. The Study on the Construction Strategies of MicroLecturesBased on the Learners' Perspective. China Educational Technology, 2015, pp.81-84

[5] Zhang Yichuan \& Qian Yangyi. The Resource Construction of Microlecture at Home and Abroad and Its Latest Application Development. Distance Education Journal, 2013, pp.26-33 